\title{
Revisiting Antitrust Limits to Probabilistic Patent Disputes: Strategic Entry and Asymmetric Information*
}

\author{
Jing-Yuan Chiou ${ }^{\dagger} \quad$ Richard Schmidtke ${ }^{\ddagger}$
}

July 2010

\begin{abstract}
We consider separately strategic entry and asymmetric information in the design of the settlement policy governing patent disputes, with a focus on Shapiro (2003)'s consumer protection rule. We show that, when a potential entrant strategically incurs an entry cost before engaging in a patent dispute, a more stringent settlement policy of deterring costly entry is preferable to the patent-holder and may lead to higher static efficiency. Concerning asymmetric information, when the disputants, but not the court, learn the patent validity, we derive an "expectation test," which requires that a laxer settlement policy be coupled with higher expected patent validity under settlement.
\end{abstract}

Keywords: Probabilistic Patents, Antitrust Limits, Patent Settlements.

JEL codes: O3, L1, L4, K4

*Previously circulated under the title "Patent Settlements and Market Entry." We would like to thank Bronwyn Hall, Monika Schnitzer, Konrad Stahl, Jean Tirole, and seminar and conferences participants at Mannheim, Munich, Nürnberg, Vienna, IESE Barcelona, and Manchester for helpful comments. All errors are our own.

${ }^{\dagger}$ Corresponding author: IMT Lucca, Piazza San Ponziano 6, 55100 Lucca, Italy; (email: jy.chioiu@imtlucca.it).

‡Department of Economics, University of Munich; (email: Richard@schmidtke.info). 


\section{Introduction}

The settlement of patent disputes ${ }^{1}$ is a two-edged sword. It avoids uncertainty, saves private litigation costs, and conserves judicial resources. It can also mask firms' intention to monopolize the market under settlement arrangements. ${ }^{2}$ How to properly regulate settlements becomes even more difficult once we acknowledge that intellectual property rights (IPRs) are state-created monopoly rights, and that very often patent rights are probabilistic rather than ironclad (Lemley and Shapiro, 2005). ${ }^{3}$

Consider a simple situation (adopted from Shapiro (2003)). A patent-holder serves as a monopolist in a market thanks to her patent. To enter the market, a potential entrant needs to clear the patent barrier either by invalidating the patent or by earning a court decision of no infringement. Alternatively, the two parties may wish to settle the patent dispute in order to advance their joint interest. In this case (and assume away secret dispute and settlement), the settlement agreement proposed by the disputants has to be approved by the court or antitrust authority. For simplicity, suppose that both parties as well as the court agree that, if fully tried, the patent-holder will prevail (i.e., the patent will be valid and the potential entrant will be infringing) with probability $\alpha \in[0,1]$.

When $\alpha=1$, there is no doubt that the entrants infringes on a valid patent. By the exclusive power granted by the patent law, the patent-holder is entitled to the monopoly and thus any settlement that would confine the monopoly power within the same market should be allowed, ${ }^{4}$ even if it exactly replicates the monopoly outcome. By contrast, if $\alpha=0$, i.e., the patent is not valid or the potential entrant is not infringing, then the economy shouldn't suffer from the mere presence of an unwarranted patent grant, and any settlement that would soften competition should be

\footnotetext{
${ }^{1}$ Or, more generally, the licensing of patent rights, as put in Shapiro (2003): "Virtually every patent license can be viewed as a settlement of a patent dispute."

${ }^{2}$ The United States Department of Justice (DOJ) and Federal Trade Commission (FTC) Antitrust Guidelines for the Licensing of Intellectual Property states: "Antitrust concerns may arise when a licensing arrangement harms competition among entities that would have been actual or likely potential competitors in a relevant market in the absence of a license (entities in a "horizontal relationship"). A restraint in a licensing arrangement may harm such competition, for example, if it facilitates market division or price fixing." http://www.ftc.gov/os/2002/07/genericdrugstudy.pdf

${ }^{3}$ The tension between intellectual property rights and antitrust has long been recognized in the literature. See, among others, Hovenkamp et al. (2004).

${ }^{4}$ This is the "derived reward" principle advocated by Maurer and Scotchmer (2006). In the U.S., the court has long held as patent misuse the extension of one's monopoly power, facilitated by patent rights, to the market of unpatented goods via tying (Merges , 1997).
} 
prohibited. But what if $\alpha \in(0,1)$ and there is uncertainty about the validity and/or infringement in the case under consideration ${ }^{5}$

Intuitively, the market performance under a "reasonable" settlement arrangement should reflect the underlying case quality: Less competition is more tolerable only when $\alpha$ is higher. A straightforward solution would be to prohibit settlement and let the disputing parties and society take the court "lottery," where monopoly and unconstrained competition are realized with probability $\alpha$ and $1-\alpha$, respectively. The process toward a court's decision may involve efficiency loss, however. In addition to the resources spent in a legal contest, society may be "risk averse" and wish to avoid uncertainty (Shapiro, 2003). A settlement can improve social welfare by providing determinacy.

To capitalize on this social benefit, Shapiro (2003) proposes what we shall call the "Shapiro policy" or the "consumer protection rule": A settlement is acceptable if "the proposed settlement generates at least as much surplus for consumers as they would have enjoyed had the settlement not been reached and the dispute instead been resolved through litigation." According to Shapiro (2003), this policy maintains a sound balance between patent law and antitrust policy, for it fully respects a patent-holder's rights as well as Pareto dominates the continuation of the law suit. ${ }^{6}$ After all, if consumers are unharmed, why wouldn't a voluntary settlement benefit the private disputants and bring Pareto improvement? (To be sure, this assertion requires that no other parties are affected by the settlement. A generalized version would require no third parties be harmed by the proposed settlement.)

In this paper, we examine this policy in two environments. First we point out that the two nice properties asserted by Shapiro (2003) hold only under a "comprehensive contracting" assumption, where no player makes strategic moves prior to the dispute. Suppose that, before engaging in a patent dispute, a potential entrant makes a unilateral decision whether to incur an entry cost. In this case, his entry decision depends on what would be gained in a patent dispute, which in turn hinges on the settlement term permitted by the court. We show that whenever the entrant can get

\footnotetext{
${ }^{5}$ Therefore, according to the classification of Hovenkamp et al. (2003), we are concerned with the "third category" where the court has to look into the validity of the patents or infringement issues involved to decide the reasonable settlement agreements. However, unlike their analysis, we consider the final market outcome under settlement rather than particular licensing arrangements such as field-of-use restrictions or reverse payment.

${ }^{6}$ Shapiro (2003) also argues that, in practice, DOJ and FTC enforcement actions are consistent with this policy.
} 
a share of the settlement surplus, a more lenient settlement agreement will encourage more entry and widen the range of entry cost over which this cost will be incurred. The effect is similar to Rasmusen (1988)'s "entry for buyout" story or the occurrence of "nuisance suits" in the law and economic literature, and would call for a more stringent settlement regulation in order to avoid unwanted strategic entry. ${ }^{7}$ As we will see, if the entry cost is large enough, even a very tight policy that prevents any settlements can outperform the Shapiro policy, in terms of both static social welfare and patentee's payoff. By deterring costly entry and thus preventing a patent dispute, the patent-holder maintains the monopoly and society saves on the entry cost. In other words, raising R\&D incentives (by increasing a patent-holder's payoff) and imposing restrictive antitrust limits need not be at odds. ${ }^{8}$

We next turn to an implementation issue of the settlement regulation, namely, asymmetric information between the court and disputing parties concerning the "case quality" $\alpha$, which measures the patent validity and likelihood of infringement. ${ }^{9}$ This information, as suggested above, is crucial in constructing a reasonable settlement policy. However, when deciding whether to grant a "pass," without injecting significant efforts into understanding the underlying technologies, the court may only have a very vague idea about the "quality" of patent rights involved. The two disputing parties, by contrast, may gather more information and even reach a consensus about each other's winning probability through extensive interactions during the bargaining process. Lacking other means to screen this information, we show that disputants will agree to settle under the court-regulated terms only when $\alpha$ is low enough, i.e., only when the patent is likely to be invalid or not infringed.

In light of this adverse selection issue, we derive an "expectation test" as an extension of the Shapiro policy under asymmetric information. To ensure that consumer surplus is at least as large as no settlement at all, this test requires that, if the court permits a more lenient settlement policy, those settled cases should have a higher "quality" $\alpha$ in expectation. We also show that in this case consumer protection is not

\footnotetext{
${ }^{7}$ See Rasmusen (1998), Daughety (1999), and Spier (2007) for surveys of nuisance suits. Different from previous studies, in our context we emphasize the effect of the settlement policy on the size of the stake to initiate a "nuisance suit," i.e., when the entrant will not incur the entry fee without a settlement.

${ }^{8}$ Meurer (1989) has also considered settlements between a patentee and a competitor under varying antitrust limits. Different from our model, his competitor is already in the market, or equivalently, there is no entry cost.

${ }^{9}$ The antitrust authority also faces information constraints in merger control (Cosnita and Tropeano, 2006, Rey, 2006) and enforcement against tacit collusion (Besanko and Spulber, 1989).
} 
compatible with full settlement as long as $\alpha=1$ with probability strictly between zero and one. And in some cases, it may even require no settlement with probability one! The Shapiro settlement policy may appear stringent in the presence of asymmetric information.

The paper proceeds as follows: In Section 2 we introduce the model. In Section 3 we consider strategic entry. Asymmetric information is introduced in Section 4 and we conclude the paper in Section 5.

\section{Model}

Two private players, a patent-holder (she) and a potential entrant (he), may engage in a patent dispute. If so, they may decide to settle the case, and the proposed settlement agreement has to be approved by the court (or antitrust authority).

The patent-holder is already operating in the market. To enter the market, the potential entrant has to incur an entry cost $f \geq 0$ and clear the legal hurdle created by the patent-holder's patent rights. Either the patent-holder may sue the entrant for patent infringement or the latter may try to invalidate the patent. ${ }^{10}$ For simplicity, we do not consider litigation costs. ${ }^{11}$ When the dispute is resolved in court without a settlement, let $\alpha \in[0,1]$ be the probability that the court finds the entrant infringes on the patent-holder's valid patent. Henceforth we shall refer to $\alpha$ as the patent validity. But it should be understood that it evaluates both validity and infringement issues. We assume that both $f$ and $\alpha$ are common knowledge between private players. The court also knows $f$, but learns the true value of $\alpha$ only in Section 3, but not in Section 4. We also assume away secret settlement, and so any dispute resolution between the patent-holder and potential entrant is scrutinized by the court.

An unsettled dispute gives rise to either a monopoly or duopoly market. The patent-holder enjoys monopoly profit $\pi^{m}$ if the potential entrant does not enter the market and there is no patent dispute, or, after a legal fight, the court rules in the patentee's favor and grants an injunction against the entrant. In this case, the con-

${ }^{10}$ The two types of lawsuits are equivalent in a two-firm setting, because a patent could block entry only when it is both valid and infringed. When there are multiple entrants with differentiated products, it may well happen that only a subset of products infringe the valid patent. In this case, the patent-holder loses the monopoly but infringing firms won't be able to enter without the patent-holder's consent.

${ }^{11}$ For strategic entry, a positive litigation cost generates no new insights but moves the threshold values of the entry costs where settlement or market entry occurs. See Meurer (1989). For asymmetric information, see the discussion in Remark 6. 
sumer surplus is denoted by $C S^{m}$. The static social welfare is $W^{m} \equiv C S^{m}+\pi^{m}$, gross of the entry cost $f$, if incurred. ${ }^{12}$

In a duopoly market, where both firms compete in an unconstrained manner, we assume that the patent-holder gets $\pi_{P}^{c} \geq 0$ and the entrant gets $\pi_{E}^{c} \geq 0$ (gross of entry cost $f$ ), respectively. This applies when the court finds no patent infringement and the entrant competes with the patent-holder in the market. Denote consumer surplus as $C S^{c}$. The static social welfare (gross of entry cost) is $W^{c} \equiv C S^{c}+\pi^{c}$, where $\pi^{c} \equiv \pi_{P}^{c}+\pi_{E}^{c}$. Assume that $\pi^{m} \geq \pi^{c} \geq 0, C^{c} \geq C S^{m} \geq 0$ and $W^{c} \geq W^{m}$.

Instead of waiting for the court to rule, firms frequently settle their patent disputes. Barring secret settlement, however, the parties' ability to cooperate and realize higher joint profit is constrained by the settlement terms permitted by the court. For simplicity, we assume that the court has all the demand and cost information to calculate the performance under different market structures. To fix the idea, let the court regulate the post-settlement market price $p \in\left[p^{c}, p^{m}\right]$, where $p^{c}$ and $p^{m}$ is the market price under duopoly and monopoly, respectively. ${ }^{13}$ We exclude the structure regulation, e.g., how many firms should be present in the market. In our setting, there is no loss in giving up this policy instrument.

For instance, under the most stringent regulation, $p=p^{c}$, firms are allowed at most a lump-sum transfer in a settlement, with joint profit $\pi^{c}$. The court will not allow any other licensing terms that would undermine competition, such as price fixing, quantity restrictions, per-unit royalties, or territory agreements. On the other hand, under the laxest settlement policy, $p=p^{m}$, firms have full degree of freedom to construct licensing agreements. In the absence of bargaining frictions such as asymmetric information, they can jointly realize the monopoly profit with proper mechanisms and then use fixed payments to divide the joint profit $\pi^{m}$. Borrowing from Meurer (1989), the policy $p=p^{c}$ is called the lump-sum policy, and $p=p^{m}$ the laissez-faire policy.

We will also pay attention to a settlement policy put forward by Shapiro (2003), under which settlements are allowed as long as consumers are no worse off than if the suit continues.

Given a market price $p$, let $C S(p)$ and $\pi(p)$ be the consumer surplus and firms'

\footnotetext{
${ }^{12}$ The net social welfare is $W^{m}-f$ if the entrant did incur $f$ and enter, but then the court rules that he infringes the patent and so is forced to exit the market.

${ }^{13}$ The same outcome can be implemented, for instance, by imposing a specific range of royalty rate in order to achieve the corresponding level of consumer surplus.
} 
joint profit (gross of entry cost $f$ ), respectively. By convention, assume that $d C S / d p<$ 0 and $d \pi / d p>0$ for $p \in\left[p^{c}, p^{m}\right]$. In other words, a lower $p$ corresponds to a more stringent settlement regulation. Following Shapiro (2003), we impose the following assumption on the shape of static social welfare, $W(p) \equiv C S(p)+\pi(p)$.

Assumption. $W(p)$ is decreasing and concave in $p$.

The different impacts of $p$ on $W$ and $\pi$ illustrate the fundamental conflicts between market power and static efficiency; absent this conflict settlement regulation is not an issue. And the concavity of $W(p)$ captures the social benefit of a settlement to avoid uncertainty. This implies a "risk-averse" social preference: $W\left(\alpha p^{m}+\right.$ $\left.(1-\alpha) p^{c}\right) \geq \alpha W^{m}+(1-\alpha) W^{c}$. That is, society would prefer a deterministic price $p=\alpha p^{m}+(1-\alpha) p^{c}$ to a "litigation lottery" where monopoly price $p^{m}$ and duopoly price $p^{c}$ are realized with probability $\alpha$ and $1-\alpha$, respectively. The concavity is guaranteed by a weakly convex industry-wide cost function and a demand function that is not "too convex". ${ }^{14}$ More importantly, this assumption gives settlements the "benefits of doubt" and works against our position in favor of a stringent antitrust policy. If the reverse is true, then the concern of static welfare calls for the prohibition of settlements. $^{15}$

To characterize the bargaining outcome, we assume that with probability $\beta \in[0,1]$ (probability $1-\beta$ ), the entrant (the patent-holder, respectively) makes a take-it-orleave-it offer. The description of the timing will be provided in due course.

\section{Strategic Entry and Antitrust Limits}

This section considers the effect of strategic entry on settlement policy. Assume that the court learns the true value of $\alpha$, which is strictly between zero and one in order to maintain uncertainty. Let us consider two scenarios, comprehensive contracting and strategic entry.

\footnotetext{
${ }^{14}$ With a industry-wide cost function $c(\cdot)$ and demand function $D(p)$,

$\frac{d W(p)}{d p}=\left[p-c^{\prime}(D(p))\right] D^{\prime}(p)<0$, and $\frac{d^{2} W(p)}{d p^{2}}=\left[p-c^{\prime}(D(p))\right] D^{\prime \prime}(p)+\left[1-c^{\prime \prime}(D(p)) D^{\prime}(p)\right] D^{\prime}(p)$,

where $p>c^{\prime}(D(p)) \cdot d^{2} W / d p^{2}$ is negative if $c^{\prime \prime} \geq 0$ and $D^{\prime \prime}$ not too large, say, $D^{\prime \prime} \leq 0$.

${ }^{15}$ But to the extent that the two disputing parties can write a contract with random components to mimic the litigation outcomes, they always (weakly) prefer to settle.
} 
Comprehensive contracting:

\begin{tabular}{ccl}
1 & 2 & 3 \\
\hline $\begin{array}{c}\text { suing and } \\
\text { bargaining }\end{array}$ & $\begin{array}{l}\text { settlement or } \\
\text { court verdict }\end{array}$ & $\begin{array}{l}\text { entry upon } \\
\text { no infringement }\end{array}$
\end{tabular}

Strategic entry:

\begin{tabular}{cccc}
0 & 1 & 2 & 3 \\
\hline & 1 & $\mid$ & $\mid$ \\
\hline $\begin{array}{l}\text { entry before } \\
\text { bargaining }\end{array}$ & suing and & settlement or & entry upon \\
bargaining & court verdict & no infringement
\end{tabular} t

Figure 1: Timings

Referring to Figure 1, in the case of comprehensive contracting (the upper time line), the entrant and patent-holder start a patent dispute at time 1 and bargain for settlement without the former spending the entry cost $f$. The proposed settlement agreement will be evaluated by the court at time 2 . If the court approves the agreement, the game ends; otherwise the trial continues and the court will make its infringement or validity decision. And at time 3 the entrant decides whether to spend $f$ and enter if and only if the court clears the patent barrier. In this scenario, entry decision forms part of the settlement bargaining. That is, the two disputants collectively decide whether $f$ should be spent in a settlement agreement.

In the case of strategic entry (the lower time line), the entrant can decide unilaterally whether to spend $f$ at time 0 , before the patent dispute and settlement bargaining. The game then continues as in the comprehensive contracting case, in particular the entrant can still wait and decide whether to enter at time 3, until settlement breaks down and the court rules in his favor. The key difference between the two scenarios is whether the potential entrant has a strategic move prior to the bargaining stage.

Let us first consider the case of strategic entry. When $f \leq \pi_{E}^{c}$, the entrant has a credible threat to enter after the patent obstacle is cleared at time 3. He doesn't have to incur $f$ at time 0 in order to start the suit and engage in bargaining with the patentholder; at time 1, the patent-holder will agree to talk with the entrant whether the latter has spent $f$ or not. And if $f$ is not spent yet, the threat point payoffs at time 1's 
bargaining are $(1-\alpha)\left(\pi_{E}^{c}-f\right)$ for the entrant and $\alpha \pi^{m}+(1-\alpha) \pi_{P}^{c}$ for the patentholder. These are the payoffs when they fail to settle the case. Their joint payoff is $\pi(p)$, where $p$ is the settlement price permitted by the court. ${ }^{16}$ The two will agree to settle when $\pi(p) \geq \alpha \pi^{m}+(1-\alpha)\left(\pi^{c}-f\right)$, or when $S(p) \equiv \pi(p)-\left[\alpha \pi^{m}+(1-\right.$ $\left.\alpha) \pi^{c}\right] \geq-(1-\alpha) f$. Define $\tilde{p}$ such that $S(\tilde{p}) \equiv-(1-\alpha) f$. There is settlement when $p \geq \tilde{p}$.

Suppose that $p \geq \tilde{p}$. With probability $\beta$, the entrant makes a take-it-or-leaveit settlement offer such that the patent-holder receives her threat point payoff. The entrant's payoff is

$$
\begin{aligned}
& \beta\left\{\pi(p)-\left[\alpha \pi^{m}+(1-\alpha) \pi_{P}^{c}\right]\right\}+(1-\beta)(1-\alpha)\left(\pi_{E}^{c}-f\right) \\
= & (1-\alpha)\left(\pi_{E}^{c}-f\right)+\beta[S(p)+(1-\alpha) f],
\end{aligned}
$$

and the patent-holder's payoff is

$$
\begin{aligned}
& (1-\beta)\left[\pi(p)-(1-\alpha)\left(\pi_{E}^{c}-f\right)\right]+\beta\left[\alpha \pi^{m}+(1-\alpha) \pi_{P}^{c}\right] \\
= & \alpha \pi^{m}+(1-\alpha) \pi_{P}^{c}+(1-\beta)[S(p)+(1-\alpha) f] .
\end{aligned}
$$

The patent-holder's payoff is increasing in the antitrust policy $p$. A more lenient policy increases the bargaining surplus without affecting the occurrence of the dispute.

On the other hand, if $f>\pi_{E}^{c}$, the entrant won't be able to get the patent-holder to the bargaining table without incurring $f$ at time 0 , regardless of the permissible settlement price. Because the potential entrant will not enter even when the patent is invalidated or there is no infringement, the patent-holder can maintain her monopoly status in the subgame where $f$ is not spent at time $0 .{ }^{17}$ But if the entrant spends $f$ at time 0 , this cost becomes sunk at the bargaining stage and the entrant's threat point payoff shifts to $(1-\alpha) \pi_{E}^{c}$. Upon dispute, the two will agree to settle if $S(p) \geq 0$, or, equivalently, if $p \geq \hat{p}$, where $\hat{p}$ is defined by $S(\hat{p}) \equiv 0$.

When $p<\hat{p}$ and so there is no settlement, the entrant's payoff is $(1-\alpha) \pi_{E}^{c}-f$, and the patent-holder's payoff is $\alpha \pi^{m}+(1-\alpha) \pi_{P}^{c}$. And when $p \geq \hat{p}$, the entrant's payoff becomes

$$
-f+\beta\left\{\pi(p)-\left[\alpha \pi^{m}+(1-\alpha) \pi_{P}^{c}\right]\right\}+(1-\beta)(1-\alpha) \pi_{E}^{c}=(1-\alpha) \pi_{E}^{c}+\beta S(p)-f,
$$

\footnotetext{
${ }^{16}$ They can save on the entry cost and simply implement $p$ because the court does not require entry.

${ }^{17}$ And any strictly positive litigation cost suffices to discourage the potential entrant from engaging in a dispute.
} 
and the patent-holder's payoff is

$$
(1-\beta)\left[\pi(p)-(1-\alpha) \pi_{E}^{c}\right]+\beta\left[\alpha \pi^{m}+(1-\alpha) \pi_{P}^{c}\right]=\alpha \pi^{m}+(1-\alpha) \pi_{P}^{c}+(1-\beta) S(p) .
$$

The entrant will incur $f$ at time 0 if and only if

$$
\pi_{E}^{c}<f \leq(1-\alpha) \pi_{E}^{c}+\beta S(p)
$$

which is possible only when $\beta S(p)>\alpha \pi_{E}^{c}$. Without the prospect of a settlement, the entrant will not spend $f$ and enter in the first place. Since a more lenient antitrust policy increases $S(p)$, it also enlarges the range of entry cost $f$ that the entrant is willing to spend in order to solicit a settlement offer. This is similar to Rasmusen (1988)'s idea of "entry for buyout," i.e., the entrant spends $f$ not to compete with the patent-holder, but to reach a settlement and share the surplus. ${ }^{18}$

Proposition 1. (Strategic entry). Given the settlement policy $p$, consider different ranges of $f$ in the strategic entry scenario:

- when $f \leq \pi_{E}^{c}$, the occurrence of patent disputes is not affected by the antitrust policy $p$. The case settles when $p \geq \tilde{p}$ and the entrant needs not spend $f$ at time 3 ; and for $p<\tilde{p}$, there is no settlement and the entrant incurs $f$ at time 3. The patent-holder's profit is increasing in $p$. Static social welfare is $W(p)$ for $p \geq \tilde{p}$, and $\alpha W^{m}+(1-\alpha)\left(W^{c}-f\right)$ otherwise;

- when $\pi_{E}^{c}<f \leq(1-\alpha) \pi_{E}^{c}+\beta S(p)$, given that $\beta S(p)>\alpha \pi_{E^{\prime}}^{c}$, the entrant has to incur $f$ at time 0 in order to have a credible litigation threat at time 1 . Static social welfare is $W(p)-f$; and

- when $f>(1-\alpha) \pi_{E}^{c}+\beta S(p)$, the patent-holder retains the monopoly.

Now we turn to the comprehensive contracting scenario. It is equivalent to eliminate time 0 in the previous game. By Proposition 1 , when $f \leq \pi_{E}^{c}$ the fact that time 0 is not available to the entrant doesn't affect the analysis. And when $f>\pi_{E}^{c}$, losing the ability to make a strategic entry decision renders the patent-holder the monopoly position. Therefore, under comprehensive contracting the antitrust policy doesn't affect the occurrence of a patent dispute. Whenever a dispute happens, the patent-holder will always prefer a more lenient policy. Upon dispute, the patent-holder's payoff is

18 "Entry for buyout" is by no means confined to the case of single entrant. In the appendix we show that this result is robust to a case of two potential entrants who decide sequentially whether to incur the entry cost and initiate the patent litigation (Rasmusen (1988) has considered the case of simultaneous entry). 
$\alpha \pi^{m}+(1-\alpha) \pi_{P}^{c}+(1-\beta) \max \{0, S(p)+(1-\alpha) f\}$, which is increasing in the policy $p$; and static social welfare is $W(p)$ for $p \geq \tilde{p}$, i.e., when there is settlement, and $\alpha W^{m}+(1-\alpha)\left(W^{c}-f\right)$ for $p<\tilde{p}$, i.e., when the two parties will not settle.

Concerning static efficiency, total static surplus under laissez-faire policy $p^{m}$ is strictly less than other policies $p \in\left[\tilde{p}, p^{m}\right)$. This is not surprising because for the policy range $p \in\left[\tilde{p}, p^{m}\right]$ the two parties will agree to settle, with a static social welfare $W(p)$ strictly decreasing in $p$. What is more interesting is when we consider the consumer protection rule proposed by Shapiro (2003).

Define the Shapiro policy $p^{s}$ by $C S\left(p^{s}\right) \equiv \alpha C S^{m}+(1-\alpha) C S^{c}$. That is, consumer surplus is the same under this policy as it would be if the suit continues. ${ }^{19}$ By the concavity assumption, $\pi\left(p^{s}\right) \geq \alpha \pi^{m}+(1-\alpha) \pi^{c},{ }^{20}$ therefore $p^{s} \geq \tilde{p}$ and $W\left(p^{s}\right) \geq$ $\alpha W^{m}+(1-\alpha)\left(W^{c}-f\right)$. Relative to no settlement, Shapiro policy $p^{s}$ does improve static social welfare. In fact, this is true for any policy $p \in\left[\tilde{p}, p^{s}\right]$ such that it induces settlement without hurting consumers. Under comprehensive contracting, it is not optimal to choose a very stringent antitrust policy.

Proposition 2. (Comprehensive contracting). Under the comprehensive contracting environment, the potential entrant has a credible entry threat, and so the patent dispute will ensue if and only if $f \leq \pi_{E}^{c}$.

When $f \leq \pi_{E}^{c}$, the patent-holder always prefers a more lenient antitrust policy; and for static efficiency, (i) the laissez-faire policy $p^{m}$ is a dominated policy; (ii) any policy $p \in\left[\tilde{p}, p^{s}\right]$ under which firms are willing to settle while consumers are not harmed Pareto dominates a stringent policy $p^{\prime}<\tilde{p}$ that prevents settlement.

The previous results confirm Shapiro (2003)'s assertion that $p^{s}$ always brings Pareto improvement under comprehensive contracting environment. However, a comparison between the two scenarios shows that it may no longer be true under strategic entry, when the entry cost falls into the range $\left(\pi_{E}^{c},(1-\alpha) \pi_{E}^{c}+\beta S(p)\right]$. In this sense, when the entry dynamics is included, "comprehensive contracting" is a crucial assumption for Shapiro (2003)'s analysis.

\footnotetext{
${ }^{19}$ More generally, the Shapiro policy allows any settlement agreement with consumer surplus no smaller than $C S\left(p^{s}\right)$. But since consumer surplus is decreasing while firms' joint profit is increasing in the policy variable $p$, firms will optimally choose $p$ such that consumers are equally well off with or without the settlement.

${ }^{20}$ To see this, suppose that at $p^{s}, \pi\left(p^{s}\right)<\alpha \pi^{m}+(1-\alpha) \pi^{c}$, and so $W\left(p^{s}\right)<\alpha W^{m}+(1-\alpha) W^{c} \leq$ $W\left(\alpha p^{m}+(1-\alpha) p^{c}\right)$, by the concavity of $W$. This in turn implies $p^{s}>\alpha p^{m}+(1-\alpha) p^{c}$. But since $C S(p)=$ $\int_{p}^{\infty} D(t) d t$, where $D(\cdot)$ is the demand function, $C S^{\prime \prime}(p)=-D^{\prime}(p)>0, C S$ is convex in $p$. The definition of $p^{s}$ and convexity of $C S$ lead to $p^{s}<\alpha p^{m}+(1-\alpha) p^{c}$, a contradiction.
} 
When the entrant has the opportunity to incur $f$ before the bargaining stage, by Proposition 1 it will expand the potential entrant's relevancy. The range of $f$ over which a patent dispute will occur and the patent-holder will lose her monopoly rent enlarges to $f \leq(1-\alpha) \pi_{E}^{c}+\beta S(p)$. Therefore, under strategic entry the patent-holder doesn't always benefit from a more lenient settlement regulation. Rather, she has "lexicographic" preferences: A policy that keeps the potential entrant out of the market serves her interests best; and conditional on entry, a laxer policy is preferable. Because a lower $p$ reduces bargaining surplus $S(p)$ and is more likely to deter entry, the patent-holder's preferences may be non-monotonic in the antitrust policy. When $f \in\left(\pi_{E^{\prime}}^{c}(1-\alpha) \pi_{E}^{c}+\beta S\left(p^{s}\right)\right]$, by $S\left(p^{c}\right)<0$ the patent-holder would prefer the most stringent settlement regulation $p^{c}$ to $p^{s}$.

Concerning static efficiency, a more lenient antitrust policy encourages the potential entrant to incur the entry fee at time 0 , and so reduces the occurrence of monopoly outcome. This improvement, however, is achieved at a cost $f$. Again, comparing $p^{s}$ with $p^{c}$ for an entry fee $f \in\left(\pi_{E}^{c},(1-\alpha) \pi_{E}^{c}+\beta S\left(p^{s}\right)\right]$, static social welfare is higher under $p^{c}$ than under $p^{s}$ if $W^{m}>W\left(p^{s}\right)-f$. (Below we present an example.)

Corollary 1. In the dynamic entry setting, relative to the most stringent policy $p^{c}$, the Shapiro policy $p^{s}$ is always friendlier to the patent-holder and improves static efficiency only under the comprehensive contracting assumption.

To be sure, the analysis here is not to deny the benefit third-party patent challenges may bring. For instance, when $f \leq \pi_{E}^{c}$, antitrust policy has no impact on the occurrence of the patent dispute, whatever the entry scenario. When there is settlement, society benefits from the entrant's presence: $W(p)>W^{m}$ so long as $p<p^{m}$. And if there is no settlement, a small $f$ also means that static welfare is more likely to be higher: $\alpha W^{m}+(1-\alpha)\left(W^{c}-f\right)-W^{m}=(1-\alpha)\left(W^{c}-W^{m}-f\right)$. In this regard, a more efficient entrants (the one with $f \leq \pi_{E}^{c}$ ) should be more welcome than its less efficient counterpart (the one with $f>\pi_{E}^{c}$ ) as socially valuable "private attorney general." The following example suggests that the same may hold true when efficiency is measured in terms of marginal cost. An entrant with higher marginal cost is more likely to engage in entry for buyout, and so a lenient antitrust policy (such as the Shapiro policy) may be less likely to improve social welfare ${ }^{21}$

Example. (Cournot competition). Consider Cournot competition with a liner inverse market demand $p=1-b Q$. Firms offer homogeneous goods, but have different

\footnotetext{
${ }^{21}$ We thank a referee for bringing our attention to this issue.
} 
marginal costs, which are assumed constant. For simplicity, assume that the patenholder has zero marginal cost. The entrant's marginal cost is $1 / 2-e$, where $e \in$ $[0,1 / 2]$. A higher $e$ then corresponds to a more efficient entrant. Under these assumptions, the monopoly outcome is $p^{m}=1 / 2, Q^{m}=1 /(2 b), \pi^{m}=1 /(4 b)$, and $C S^{m}=1 /(8 b)$; and the duopoly outcome is

$$
\begin{aligned}
& p^{c}=\frac{1}{2}-\frac{e}{3}, q_{P}^{c}=\frac{1}{b}\left(\frac{1}{2}-\frac{e}{3}\right), q_{E}^{c}=\frac{2 e}{3 b}, Q^{c}=\frac{1}{b}\left(\frac{1}{2}+\frac{e}{3}\right), \text { and } \\
& \pi_{P}^{c}=\frac{1}{b}\left(\frac{1}{2}-\frac{e}{3}\right)^{2}, \pi_{E}^{c}=\frac{4 e^{2}}{9 b}, C S^{c}=\frac{1}{2 b}\left(\frac{1}{2}+\frac{e}{3}\right)^{2} .
\end{aligned}
$$

The case of $e=0$ corresponds to the monopoly outcome. The entrant's marginal cost is equal to the monopoly price; and with zero margin, the entrant will not produce. When $e=1 / 2$, the entrant is as efficient as the patent-holder, and we have the standard symmetric Cournot outcome. ${ }^{22}$

We want to find a case where $\pi_{E}^{c}<f \leq(1-\alpha) \pi_{E}^{c}+\beta S\left(p^{s}\right)$ and $W^{m}>W\left(p^{s}\right)-f$. That is, under the Shapiro policy, the entrant will incur the entry cost in order to induce a settlement, and social welfare is lower than if the entry is deterred, e.g., by the lump-sum policy (due to no settlement). As an illustration, we set $f$ at the upper bound level, $f=(1-\alpha) \pi_{E}^{c}+\beta S\left(p^{s}\right)$. The first condition then requires $\beta S\left(p^{s}\right)>\alpha \pi_{E^{\prime}}^{c}$ and the second condition amounts to

$$
(1-\alpha)\left(C S^{c}-C S^{m}\right)<(1-\alpha)\left(\pi^{m}-\pi_{P}^{c}\right)-(1-\beta) S\left(p^{s}\right)
$$

We look for the values of $e$ such that $S\left(p^{s}\right)>\alpha \pi_{P}^{c}$ and $C S^{c}-C S^{m}<\pi^{m}-\pi_{P}^{c}$. Whenever they hold, there are values of $\beta$ sufficiently large such that the original conditions are satisfied.

The Shapiro policy here is determined by

$$
C S\left(p^{s}\right)=\frac{\left(1-p^{s}\right)^{2}}{2 b} \equiv \alpha C S^{m}+(1-\alpha) C S^{c} \Rightarrow p^{s}=1-\sqrt{\frac{1}{4}+(1-\alpha) \frac{e}{3}\left(1+\frac{e}{3}\right)} .
$$

Since the entrant is less efficient than the patent-holder, in the settlement, the two firms will jointly decide to implement $p^{s}$ and let the patent-holder serve all the market

\footnotetext{
${ }^{22}$ Our purpose here is to show when entry may reduce welfare. If, by contrast, the entrant has lower marginal cost than the patent-holder, then entry provides an additional benefit of superior production technology.
} 
$Q^{s}=\left(1-p^{s}\right) / b$. Settlement outcome is

$$
\begin{aligned}
& \pi\left(p^{s}\right)=p^{s} Q^{s}=\frac{1}{b}\left\{\sqrt{\frac{1}{4}+(1-\alpha) \frac{e}{3}\left(1+\frac{e}{3}\right)}-\left[\frac{1}{4}+(1-\alpha) \frac{e}{3}\left(1+\frac{e}{3}\right)\right]\right\}, \\
& \text { and } S\left(p^{s}\right)=\frac{1}{b}\left[\sqrt{\frac{1}{4}+(1-\alpha) \frac{e}{3}\left(1+\frac{e}{3}\right)}-\frac{1}{2}-(1-\alpha) \frac{2 e^{2}}{3}\right] \geq 0 .
\end{aligned}
$$

$S\left(p^{s}\right)=0$ if and only if $e=1 / 2$ and $\alpha=0$.

Provided that the entrant is a relevant competitor, i.e., when $e>0$,

$$
S\left(p^{s}\right)>\alpha \pi_{E}^{c} \Leftrightarrow(1-\alpha)\left(1+\frac{e}{3}\right)>\frac{2 e}{3}(3-\alpha)\left[1+\frac{2 e^{2}}{9}(3-\alpha)\right]
$$

and $\quad \pi^{m}-\pi_{P}^{c}>C S^{c}-C S^{m} \Leftrightarrow \frac{1}{2}>\frac{e}{2}$.

Condition (13) is guaranteed by $e \leq 1 / 2$. For condition (12), as long as $\alpha<1$, it holds if and only if $e$ is small enough. We thus conclude that a less efficient entrant is less likely to bring welfare-improving patent challenges.

Remark 1. (Commitment). In the case of strategic entry, the patent-holder suffers from the inability to commit to not negotiating with the potential entrant. To overcome this commitment problem, Rosenberg and Shavell (2006) proposes a simple solution to give the patent-holder the option to have the court prevent settlements. This option, however, could help the patent-holder here only when it could be exerted before time 0 , i.e., before the potential entrant incurs $f$ and surfaces as a real threat. When the entrant has spent $f$ and a dispute initiated, the patent-holder would prefer to seize any profitable settlement opportunity. The "no settlement" option is irrelevant. By contrast, a stringent settlement rule can complement the patent-holder's commitment power and prevent the dispute from arising.

Remark 2. (U.S. patent reform). The U.S. patent law requires that to be eligible to invalidate a patent in court, a party should either intend to or already have undertaken an activity carrying a significant possibility of infringement. ${ }^{23}$ In our model, it corresponds to a case where time 3 is eliminated and a patent dispute won't happen

\footnotetext{
${ }^{23}$ More precisely, a patent can only be challenged in court as an affirmative defense or counterclaim to an infringement action brought by the patentee, or by a declaratory judgment plaintiff. For the latter venue, the Court of Appeals for the Federal Circuit (CAFC) used to employ a two prong "reasonable apprehension of imminent suit" test: in order to file a declaratory judgement suit, a potential infringer must (1) show an explicit threat or other action by the patentee which creates a reasonable apprehension on the part of the declaratory judgment plaintiff that it will face an infringement suit, and (2) present activity by the declaratory judgment plaintiff which could constitute infringement, or concrete steps taken by the declaratory judgment plaintiff with the intend to conduct such activity. See Teva Pharma. USA, Inc. v. Pfizer, Inc., 395
} 
without spending the entry fee at time 0 . A comparison between this scenario and the strategic entry case reveals the effect of a policy reform to abolish this standing requirement.

For $f \in\left(\pi_{E}^{c},(1-\alpha) \pi_{E}^{c}+\beta S(p)\right]$, with or without this requirement the entrant will have to spend $f$ at time 0 in order to gain a credible threat at the bargaining stage. The policy change will have no effect when entry cost falls into this range. ${ }^{24}$ But when $f \leq \pi_{E}^{c}$, contrary to the strategic entry scenario, a legal requirement to present in the market forces the entrant to incur $f$ before the bargaining stage. Therefore, when entry cost falls in the lower end $\left(f \leq \pi_{E}^{c}\right)$, opening the court venue will improve static welfare with the magnitude of $f$ (when $p \geq \tilde{p}$ ) or $\alpha f$ (when $p<\tilde{p}$ ). This result vindicates U.S. patent reform, although the ex post effect might be modest.

Remark 3. The effect of strategic entry is not limited to the comparison between the Shapiro policy and lump-sum policy. Suppose that $f>\pi_{E}^{c}$. Consider two policies $p^{1}$ and $p^{2}$, with $p^{1}>p^{2}$ and $\beta S\left(p^{1}\right)>\alpha \pi_{E}^{c}$, i.e., the policy $p^{1}$ is loose enough so that the set $\left(\pi_{E^{\prime}}^{c},(1-\alpha) \pi_{E}^{c}+\beta S\left(p^{1}\right)\right]$ is not empty. Then whether $\beta S\left(p^{2}\right) \gtrless \alpha \pi_{E}^{c}$, there is a range of $f$ over which the potential entrant will incur $f$ under $p^{1}$ but not under $p^{2}{ }^{25}$ In this case, due to the entry deterrence effect the patent-holder will prefer $p^{2}$ to $p^{1}$. Similarly, static social welfare may be lower under $p^{1}$ than under $p^{2}$, i.e., we may have $W^{m}>W\left(p^{1}\right)-f$.

F.3d 1324, 1330 (Fed. Cir, 2005). This test, in particular the first prong, is criticized by the Supreme Court in MedImmune Inc. $v$. Genentech Inc., 127 S. Ct. 764 (2007). See, in particular, footnote 11 of the decision (http://www.law.cornell.edu/supct/pdf/05-608P.Z0). The CAFC then has switched to the Supreme Court's "all the circumstances" test in a series of decisions, e.g., SanDisk $v$. STMicroelectronics, 480 F.3d 1372 (Fed. Cir. 2007), Teva Pharma. USA, Inc. v. Novartis Pharma. Corp., 482 F.3d 1330, 1339 (Fed. Cir. 2007), and Sony Electronics, Inc. v. Guardian Media Tech. Ltd., 497 F.3d 1271 (Fed. Cir. 2007). This standard lowers the bar to file the declaratory judgement because "reasonable apprehension of suit" is no more required, instead, the court should consider all the circumstances to decide whether it has the jurisdiction.

Note that in the U.S., anyone can also challenge the validity of the patent in the patent office via the patent reexamination procedure. However, this approach is seldom taken. Graham et al. (2003) reports that only $0.3 \%$ of patents granted between 1991-8 are reexamined and half of the requests are brought by holders of the patent.

${ }^{24}$ This is no longer true when $f$ is divisible and the entrant can split $f$ and incur part of it prior to bargaining. In this case, another way to interpret the standing requirement is that, in order to initiate a patent litigation, the entrant has to at least incur a cost $f_{0} \in(0, f]$. (We thank a referee for this suggestion.) In the appendix, we show that, when $f>\pi_{E}^{c}$, maintaining a high level of standing requirement (a high $f_{0}$ ), may bring a similar benefit of discouraging wasteful entry. For all the other cases, nevertheless, the standing requirement either is irrelevant or reduces static welfare because the entrant has to spend more cost to initiate the patent dispute.

${ }^{25}$ When $\beta S\left(p^{2}\right)>\alpha \pi_{E}^{c}$, it requires $f \in\left((1-\alpha) \pi_{E}^{c}+\beta S\left(p^{2}\right),(1-\alpha) \pi_{E}^{c}+\beta S\left(p^{1}\right)\right]$; and when $\beta S\left(p^{2}\right) \leq$ $\alpha \pi_{E}^{c}$, it requires $f \in\left(\pi_{E}^{c},(1-\alpha) \pi_{E}^{c}+\beta S\left(p^{1}\right)\right]$, respectively. 
Remark 4. (Bargaining setting). Our result on strategic entry holds as long as the surplus the potential entrant can extract from bargaining, $\beta S(p)$, is increasing in the prevailing settlement policy $p$. For patent disputes, especially infringement suits, it is not uncommon for the court to grant the patent-holder a preliminary injunction to enjoin the alleged infringer from using the patented technology (Lanjouw and Lerner, 2001). In this case, the patent-holder would enjoy monopoly profit before an agreement is reached, or before the court delivers its decision. It would then be problematic to model this situation with a sequential bargaining model à la Rubinstein where bargaining can continue forever. The "inside option value" (the payoff stream during the course of bargaining) for the patent-holder is in fact her maximal payoff and so she would have every incentive to delay the bargaining process (Binmore et al., 1986).

Alternatively, if we use a sequential bargaining model with exogenous breakdown risk, e.g., at each period the court may exogenously terminate the bargaining in order to prevent exploitation of the preliminary injunction, our bargaining result is consistent with the Nash bargaining solution approximated as an equilibrium outcome of this sequential game when the length of a single bargaining period approaches to zero.

\section{Asymmetric Information Between Settling Parties and the Court}

Patent validity and infringement are complicated and technical issues. Without carefully studying the case under dispute, the court may not have an accurate assessment of each party's winning probability, captured by $\alpha$ here. ${ }^{26}$ Because the antitrust policy proposed by Shapiro (2003) is extremely sensitive to this parameter, an inevitable

\footnotetext{
${ }^{26}$ Some courts show reluctance to engage in such assessment. To cite from the District Court in In re Ciprofloxacin Hydrochloride Antitrust Litigation (2005): "In sum, it is inappropriate for an antitrust court, in determining the reasonableness of a patent settlement agreement, to conduct an after-the-fact inquiry into the validity of the underlying patent. Such an inquiry would undermine any certainty for patent litigants seeking to settle their disputes... Nor is it appropriate to discount the exclusionary power of the patent by any probability that the patent would have been found invalid."

On appeal, the Court of Appeals for the Federal Circuit affirmed the district court decision and expresses its agreement with the Second Circuit (In re Tamoxifen) and Eleventh Circuit (In re ScheringPlough) that "in the absence of evidence of fraud before the PTO or sham litigation, the court need not consider the validity of the patent in the antitrust analysis of a settlement agreement involving a reverse payment." In re Ciprofloxacin Hydrochloride Antitrust Litigation, No. 08-1097, 2008 WL 4570669 (Fed. Cir. Oct. 15, 2008, http://www. cafc.uscourts.gov/opinions/08-1097.pdf).
} 
question is what if the court has to approve settlement with less information about $\alpha$ than the disputants. ${ }^{27}$

Suppose that the true $\alpha$ is still common knowledge to the patent-holder and potential entrant. For simplicity, assume away the entry cost, $f=0$, and so strategic entry is not a concern. Both time sequences in Figure 1 will generate the same result. For the court, we assume that it doesn't know the true $\alpha$. When deciding whether to approve a settlement, the court believes that $\alpha$ is randomly distributed between $[\underline{\alpha}, \bar{\alpha}] \subseteq[0,1]$ with $C D F \Lambda(\cdot)$. If no settlement agreement is reached, the case advances to trial and the court makes its decision according to the true $\alpha$. For simplicity, assume there is no litigation cost. (See Remark 6 below for a discussion of litigation costs.)

Lacking further information, the antitrust policy $p \in\left[p^{c}, p^{m}\right]$ cannot be conditioned on the true $\alpha$. Without frictions in bargaining, private parties will accept this settlement term if and only if $\pi(p) \geq \alpha \pi^{m}+(1-\alpha) \pi^{c} .^{28}$ Given $p$, only those cases where $\alpha$ is low enough will settle.

Define

$$
C S^{0} \equiv \int_{\underline{\alpha}}^{\bar{\alpha}}\left[\alpha C S^{m}+(1-\alpha) C S^{c}\right] d \Lambda(\alpha)
$$

as (ex ante) expected consumer surplus if no settlement is allowed. An ex ante Shapiro policy $p^{*} \in\left[p^{c}, p^{m}\right]$ then requires that the expected consumer surplus under this policy is no smaller than $C S^{0}$. We show that, due to the information deficiency of the court, the antitrust policy that "keeps consumer whole" may have to be set at a stringent level so that full settlement is not guaranteed, and it may even be so tight that settlement is prohibited with probability one.

Given $p^{*}$, let $\alpha^{*} \in[\underline{\alpha}, \bar{\alpha}]$ be the cutoff between settled and unsettled types: for all $\alpha \leq \alpha^{*}, \pi\left(p^{*}\right) \geq \alpha \pi^{m}+(1-\alpha) \pi^{c}$, and for all $\alpha>\alpha^{*}, \pi\left(p^{*}\right)<\alpha \pi^{m}+(1-\alpha) \pi^{c}$. Disputants with $\alpha \leq \alpha^{*}$ will agree to settle under the policy $p^{*}$, and with $\alpha>\alpha^{*}$

${ }^{27}$ The court may not know the true $\alpha$ unless the case proceeds to the costly discovery phase and experts being summoned to analyze in court the underlying patents and/or infringing products. Up to this stage a big saving a settlement can bring, the litigation cost, has disappeared. On the other hand, the antitrust authority such as the FTC or the DOJ Antitrust Division may have expertise in estimating market performance such as demand and consumer surplus, this experience, however, can hardly carry over to evaluate patent validity and infringement.

${ }^{28}$ When $\pi(p) \geq \alpha \pi^{m}+(1-\alpha) \pi^{c}$, the two can use a fixed payment to divide the joint profit $\pi(p)$ such that both parties prefer to settle. And when $\pi(p)<\alpha \pi^{m}+(1-\alpha) \pi^{c}$, there is no division of joint profit $\pi(p)$ that can induce both parties to accept the settlement. For all $\tilde{\beta} \in[0,1]$ such that the entrant gets $\tilde{\beta} \pi(p)$ and the patent-holder gets $(1-\tilde{\beta}) \pi(p)$ under settlement, there is no way to satisfy both $\tilde{\beta} \pi(p) \geq(1-\alpha) \pi_{E}^{c}$ and $(1-\tilde{\beta}) \pi(p) \geq \alpha \pi^{m}+(1-\alpha) \pi_{P}^{c}$. 
will proceed to trial. Expected consumer surplus under $p^{*}$ is thus $\int_{\underline{\alpha}}^{\alpha^{*}} C S\left(p^{*}\right) d \Lambda+$ $\int_{\alpha^{*}}^{\bar{\alpha}}\left[\alpha C S^{m}+(1-\alpha) C S^{c}\right] d \Lambda$. Shapiro's criterion requires

$$
\begin{aligned}
& \int_{\underline{\alpha}}^{\alpha^{*}} C S\left(p^{*}\right) d \Lambda+\int_{\alpha^{*}}^{\bar{\alpha}}\left[\alpha C S^{m}+(1-\alpha) C S^{c}\right] d \Lambda \geq C S^{0} \\
\Rightarrow & C S\left(p^{*}\right) \Lambda\left(\alpha^{*}\right) \geq \int_{\underline{\alpha}}^{\alpha^{*}}\left[\alpha C S^{m}+(1-\alpha) C S^{c}\right] d \Lambda .
\end{aligned}
$$

After a few calculation, this condition can be expressed as an "expectation test:"

$$
E\left(\alpha \mid \alpha \leq \alpha^{*}\right) \geq \frac{C S^{c}-C S\left(p^{*}\right)}{C S^{c}-C S^{m}}
$$

To protect consumer the expected quality of the settled case (i.e., the validity of the disputed patent or the entrant's infringement probability) should be no smaller than the ratio of consumer welfare loss under the settlement policy $\left(C S^{c}-C S\left(p^{*}\right)\right)$ to that under monopoly pricing $\left(C S^{c}-C S^{m}\right)$. A more lenient policy ( $p^{*}$ higher) should come with a higher expected case quality under settlement.

Define $\underline{p}$ as the market price under which only the type $\underline{\alpha}$ is willing to settle: $\pi(\underline{p}) \equiv \underline{\alpha} \pi^{m}+(1-\underline{\alpha}) \pi^{c}$.

Proposition 3. (Expectation test). Suppose that the antitrust authority holds the belief that $\alpha$ is distributed in $[\underline{\alpha}, \bar{\alpha}]$ with a CDF $\Lambda(\cdot)$.

- When $\operatorname{Pr}(\alpha=\bar{\alpha}=1) \in(0,1)$, the ex ante Shapiro policy induces positive litigation probability.

- If no $p^{*}>\underline{p}$ and the corresponding $\alpha^{*}$ can pass the expectation test, then the ex ante Shapiro policy can only be implemented with litigation probability $\operatorname{Pr}(\alpha>\underline{\alpha})$, which is equal to one when $\Lambda$ is continuous. ${ }^{29}$

Proof. The second bullet is straightforward. For the first point, when $\bar{\alpha}=1>\underline{\alpha}$, any $p^{*}<p^{m}$ will trigger litigation for those $\alpha \rightarrow 1$. And if the authority sets $p^{*}=p^{m}$ to ensure full settlement, then condition (16) fails as long as $\operatorname{Pr}(\alpha=1)<1$, i.e., as long as the patent may not be ironclad.

Q.E.D.

A factor that may affect the court's prior assessment about the case quality, $\Lambda$, is the "quality control" exercised by the patent office during patent examination. When patent examiners carefully scrutinize patent applications, this should boost the confidence on the validity of issued patents and shift the distribution $\Lambda$ to the right. By the

\footnotetext{
${ }^{29}$ In fact, this is true as long as $\Lambda$ is atomless.
} 
same token, for those fields without sufficient examination efforts, granted patents may be invalidated in court (if fully tested) with significant probability. Given cutoff $\alpha^{*}$, worse performance by the patent office decreases the expected patent quality $E\left(\alpha \mid \alpha \leq \alpha^{*}\right)$. It becomes more difficult to pass the expectation test. Antitrust policy should be more stringent in response to lax quality control at the patent office.

Example. (Symmetric Cournot Competition.) Consider again linear demand $p=1-b Q$, but assume symmetric Cournot competition, i.e., $e=1 / 2$ and so both firms have zero marginal cost. Also consider uniform distribution with support $[\underline{\alpha}, \bar{\alpha}] \subseteq[0,1]$, where $\triangle \alpha \equiv \bar{\alpha}-\underline{\alpha}>0$. For this class of distributions, CDF is $\Lambda(\alpha)=(\alpha-\underline{\alpha}) / \Delta \alpha$, and so $E\left(\alpha \mid \alpha \leq \alpha^{*}\right)=\left(\alpha^{*}+\underline{\alpha}\right) / 2$.

From previous example, given market price $p^{*} \in[1 / 3,1 / 2]$, consumer surplus is $\left(1-p^{*}\right)^{2} /(2 b)$, firms' joint profit is $p^{*}\left(1-p^{*}\right) / b$, and $C S^{m}=1 /(8 b)$ as well as $C S^{c}=2 /(9 b)$. The right-hand side of condition (16) is $\left[16-36\left(1-p^{*}\right)^{2}\right] / 7$, and so with uniform distribution the condition becomes

$$
\frac{\alpha^{*}+\underline{\alpha}}{2} \geq \frac{16-36\left(1-p^{*}\right)^{2}}{7} \Rightarrow\left(1-p^{*}\right)^{2} \geq \frac{4}{9}-\frac{7}{72}\left(\alpha^{*}+\underline{\alpha}\right)
$$

where $\alpha^{*} \in[\underline{\alpha}, \bar{\alpha}]$ is the cutoff between settled and unsettled types. By indifference condition, $\alpha^{*}$ is determined by

$$
\pi\left(p^{*}\right) \equiv \alpha^{*} \frac{1}{4 b}+\left(1-\alpha^{*}\right) \frac{2}{9 b} \Rightarrow p^{*}\left(1-p^{*}\right)=\frac{2}{9}+\frac{\alpha^{*}}{36}
$$

or, $\alpha^{*}=36 p^{*}\left(1-p^{*}\right)-8$, where $p^{*} \in[1 / 3,1 / 2]$. Condition (16), then, requires that

$$
\left(1-p^{*}\right)^{2} \geq \frac{11}{9}-\frac{7}{2} p^{*}\left(1-p^{*}\right)-\frac{7}{72} \underline{\alpha} .
$$

When $\underline{\alpha}=0$, it is easy to verify that the only $p^{*} \in[1 / 3,1 / 2]$ to satisfy this condition is $p^{*}=1 / 3=p^{c}$. Only the type $\underline{\alpha}=0$ will accept this competitive price as settlement term and so the probability of no settlement is $\operatorname{Pr} .(\alpha>0)=1$.

Remark 5. (Construction of Shapiro policy). Another interpretation of the asymmetric information scenario is that, instead of one case with different possible values of $\alpha$, there is a continuum of cases with measure one, each with the same market conditions and thus the same $C S$ and $\pi$. The only difference among cases is $\alpha$, which again has a distribution function $\Lambda(\alpha)$ and support $[\underline{\alpha}, \bar{\alpha}]$. The court knows only the distribution $\Lambda$, but not the true $\alpha$ of each case.

As previously discussed, when $\bar{\alpha}=1$ the ex ante Shapiro policy must have a $\alpha^{*}<$ $\bar{\alpha}$. If the settled cases have a measure larger than zero and $\alpha^{*}>\underline{\alpha}$, then at $\alpha^{*}$ the parties 
are indifferent between settlement or not, $\pi\left(p^{*}\right)=\alpha^{*} \pi^{m}+\left(1-\alpha^{*}\right) \pi^{c}$. For $\alpha^{*}$, the $e x$ ante policy $p^{*}$ is biased toward the consumer, $C S\left(p^{*}\right)>\alpha^{*} C S^{m}+\left(1-\alpha^{*}\right) C S^{c}$ and more stringent than the ex post Shapiro policy should the court learns the true type. Shapiro policy needs to be properly interpreted by taking into account the uncertainty facing the antitrust authority, but not at the individual case level.

Remark 6. (Litigation costs). As suggested in Meurer (1989), to help the court discern the true $\alpha$ the disputing parties may need to spend a handsome litigation $\operatorname{cost} L>0$ to engage in discovery, retaining experts, etc.. Let $L$ be the aggregate litigation cost incurred by the two parties. It is easy to see that a strictly positive litigation cost will increase settlement incentives. Given settlement policy $p^{*}$, disputants are willing to settle as long as $\pi\left(p^{*}\right) \geq \alpha \pi^{m}+(1-\alpha) \pi^{c}-L$. Or, targeting a cutoff $\alpha^{*}$, the court can implement a lower settlement price $p^{* *}$ than without litigation cost. By $\pi\left(p^{* *}\right)=\alpha^{*} \pi^{m}+\left(1-\alpha^{*}\right) \pi^{c}-L$, the policy $p^{* *}$ is decreasing, and thus consumer surplus $\Lambda\left(\alpha^{*}\right) C S\left(p^{* *}\right)$ is increasing in $L$. This gain, however, has to be balanced against the expected litigation cost $\left[1-\Lambda\left(\alpha^{*}\right)\right] L$ for those unsettled cases.

\section{Concluding Remarks}

In this paper, we examined two issues that would affect the proper regulation of patent settlement, namely, strategic entry and asymmetric information. In the presence of strategic entry, a more stringent settlement rule may prevent a patent dispute from arising, and thus maintain the patent-holder's monopoly. But due to the saving on entry cost it needs not reduce static social welfare. Concerning the second issue, our analysis suggests that a settlement policy that takes into account asymmetric information between the court and settling parties may only appear stringent, in that it may prohibit settlement with some probability.

It is worth mentioning that, although for most of our analysis we focused on the consumer protection rule, mainly for its intention to balance between consumer welfare and innovation incentives, we believe that the insights derived in this paper are applicable when other criteria are used.

To advance our understanding and for better policy construction, future works should relax several assumptions imposed here. For instance, in our framework of asymmetric information, the court does not have other policy tools to sort out patent validity and thus the screening takes a rough binary form, i.e., either settlement or 
litigation. Depending on the industry or technology field, the court might have a richer set of policy instruments to design different "bundles" of settlement terms and more effectively elicit the information. It is then interesting and important to consider industry-specific settlement policy designs.

Future work should also extend to cases where patents serve more roles than preventing entry. In this paper, we've taken a very simple market structure with respect to the disputed patent, namely, a blocking patent covering a market. Although useful for early-step analysis, it is not the unique role patents serve in the business world. For instance, in a complex technology industry such as semiconductor or software, patents are also used as bargaining chips in cross-licensing agreements. Proper settlement regulation may need to respond to these strategic values of patent rights.

Lastly, we've excluded secret settlement in the model, and so any agreement by the two disputing parties is subject to court approval. Since firms have strong incentives to escape antitrust scrutiny and engage in secret settlement, future study should relax this assumption. But to the extent that the antitrust limit sets the threat point of a secret negotiation, our results concerning the impact of antitrust policy on the patentholder's profit should hold even when secret settlement is allowed.

\section{Appendix: Sequential Entry and Divisible Entry Cost}

In this appendix we consider two extensions of strategic entry and show that our results in Section 3 are robust to these modifications.

Sequential entry: Suppose that there are two potential entrants, $E_{1}$ and $E_{2}$, with entry cost $f_{i}>0$ and bargaining power $\beta_{i} \in(0,1)$ vis-à-vis the patent-holder, $i \in$ $\{1,2\} . E_{1}$ and $E_{2}$ sequentially decide whether to challenge the patent-holder's patent rights. For simplicity, we consider only disputes over patent validity, e.g., two generic drug makers challenge a patent covering a block-buster, and let $\alpha \in(0,1)$ denote the common belief that the patent is valid if contested in court. One successful strike suffices to invalidate the patent.

Label the negotiation between the patent-holder and $E_{1}\left(E_{2}\right)$ as the first round, or round one (second round or round two, respectively) bargaining. We keep the assumption that $\beta_{i}$ is the probability that an entrant $E_{i}$ makes the offer to the patentholder, and consider a sequential negotiation where: (i) the same antitrust policy $p$ 
applies to both negotiations; (ii) settlement terms are observable to all players; (iii) there is no renegotiation; in particular, $E_{2}$ does not negotiation with $E_{1}$ at the second round; and (iv) the settlement agreement at the first round void if bargaining breaks down at the second round. The first three assumptions are made to simplify the analysis of the bargaining process. We will discuss the forth assumption in Remark 7 at the end of this extension.

To show that the logic of entry for buyout extends to sequential entry, we restrict our attention to the case where neither entrant will incur the entry cost without being sure that settlement will be reached along the equilibrium path. According to the analysis in Section 3, this corresponds to the requirement that the entry cost is larger than the competition payoff. ${ }^{30}$ In the present case, however, we need to specify the competitions outcome according to whether the patent-holder is competing against only $E_{1}$, or only $E_{2}$, or both. On the other hand, we will assume an antitrust policy $p$ lenient enough, and so $\pi(p)$ large enough, such that a settlement will also be reached, given that a dispute has been initiated.

Denote the patent-holder's monopoly payoff the same as before, $\pi^{m}$. When there are only the patent-holder and an entrant $E_{i}$ competing in the market, denote the competition payoffs as $\pi_{P, i}^{d}$ for the patent-holder and $\pi_{i}^{d}$ for the entrant $E_{i}, i \in 1,2$, where the superscript " $d$ " stands for duopoly. When all three firms compete on the market, denote the competition payoffs as $\pi_{P}^{t}$ for the patent-holder and $\pi_{i}^{t}$ for the entrant $E_{i}, i \in\{1,2\}$, where the superscript " $t$ " stands for triopoly.

Assume that all the competition payoffs are greater than zero, and that $f_{i}>\pi_{i}^{d} \geq$ $\pi_{i}^{t}$ for both $i \in\{1,2\}$. The second inequality generally holds, namely, a firm's profit decreases as the number of competitors increases. By the first inequality, the patentholder will not take an entrant seriously until the latter incurs the entry cost. Incurring entry cost, as before, is a strategic move for an entrant to solicit settlement payment; we consider the strategic entry scenario for both entrants. ${ }^{31}$

\footnotetext{
${ }^{30}$ Recall the analysis in Proposition 1 . When the entry cost is smaller than competition payoff, the antitrust policy has no bite on the entrant's decision to initiate the patent challenge.

${ }^{31}$ For simplicity, we do not explicitly consider the Hatch-Waxman type temporary quasi-monopoly in the U.S. pharmaceutical industry, which grants the first challenger a 180-day exclusive period during which no other generic firms can obtain the approval to market their generic drugs. This is only quasi-monopoly because the original patent-holder can still sell its own "brand-generic" version. However, when entrants enter with the sole intention to be bought out, they will want to make sure that settlement agreements will be signed and competition outcome will no arise. With some modifications so that $\pi_{i}^{d}$ and $\pi_{i}^{t}$ reflect the competitive advantage (or disadvantage) derived from the 180-day quasi-monopoly, we believe that our results can be applied to this case.
} 
We want to show that the upper bound of entry cost that an entrant is willing to incur is increasing in the antitrust policy $p$. By backward induction, we start with the bargaining between $E_{2}$ and the patent-holder in order to analyze $E_{2}$ 's optimal decision to incur $f_{2}$. Since $E_{1}$ will not incur $f_{1}$ without the expectation of a settlement, we can ignore the subgame where the patent's validity has been fully tested in court before the second round. We need, however, to consider separately whether $E_{1}$ has incurred entry cost.

At round two, if $E_{1}$ did not incur the entry cost before, say, due to a very high $f_{1}$ (and, by assumption, has lost his chance), then the analysis is exactly the same as the single-entrant case. $E_{2}$ will incur $f_{2}$ for

$$
\pi_{2}^{d}<f_{2} \leq(1-\alpha) \pi_{2}^{d}+\beta_{2}\left[\pi(p)-\alpha \pi^{m}-(1-\alpha)\left(\pi_{P, 2}^{d}+\pi_{2}^{d}\right)\right] \equiv f_{2}^{* *} .
$$

If $E_{1}$ has incurred $f_{1}$, initiated a patent challenge, and settled with the patent-holder with a payment $b_{1}$ (from the patent-holder to $E_{1}$ ), then at the second round, the patentholder and $E_{2}$ will take $b_{1}$ as given. Without renegotiation, the cooperative payoff between the patent-holder and $E_{2}$ in a settlement is $\pi(p)-b_{1}$. Since bargaining breakdown voids prior settlement agreements, threat point payoffs are $\alpha \pi^{m}+(1-\alpha) \pi_{P}^{t}$ for the patent-holder and $(1-\alpha) \pi_{2}^{t}$ for $E_{2}$. Note that triopoly ensues after the successful invalidation of the patent, for $E_{1}$ has already incurred $f_{1}$. Bargaining surplus is $S_{2}\left(p, b_{1}\right)=\pi(p)-b_{1}-\left[\alpha \pi^{m}+(1-\alpha)\left(\pi_{P}^{t}+\pi_{2}^{t}\right)\right]$.

With probability $\beta_{2}, E_{2}$ offers the patent-holder a payoff $\alpha \pi^{m}+(1-\alpha) \pi_{P}^{t}$, and obtains a payoff $\pi(p)-b_{1}-\left[\alpha \pi^{m}+(1-\alpha) \pi_{P}^{t}\right]$. With probability $1-\beta_{2}$, the patentholder offers $E_{2}$ the payoff $(1-\alpha) \pi_{2}^{t}$, and obtains a payoff $\pi(p)-b_{1}-(1-\alpha) \pi_{2}^{t}$. The expected payoffs are $(1-\alpha) \pi_{2}^{t}+\beta_{2} S_{2}\left(p, b_{1}\right)$ for $E_{2}$ and $\alpha \pi^{m}+(1-\alpha) \pi_{P}^{t}+(1-$ $\left.\beta_{2}\right) S_{2}\left(p, b_{1}\right)$ for the patent-holder. $E_{2}$ will incur $f_{2}$ when $\pi_{2}^{c}<f_{2} \leq(1-\alpha) \pi_{2}^{t}+$ $\beta_{2} S_{2}\left(p, b_{1}\right)$. Fixing $b_{1}$, a more lenient antitrust policy $p$ will increase $\pi(p)$ and (weakly) enlarge the range of entry cost $E_{2}$ is willing to incur. On the other hand, a large enough payment $b_{1}$ may deter $E_{2}$ from initiating the challenge. The choice of $b$ at the first round may be driven by strategic concerns to deter $E_{2}$ 's entry.

Move back to the first round of negotiation, assuming that $E_{1}$ has incurred $f_{1}$. The threat point payoffs are $(1-\alpha) \pi_{1}^{d}$ for $E_{1}$ and $\alpha \pi^{m}+(1-\alpha) \pi_{P, 1}^{d}$ for the patent-holder. The duopoly outcome applies here because, by $f_{2}>\pi_{2}^{d}, E_{2}$ will not enter when facing competition for sure. The cooperative payoff, however, depends on whether $E_{2}$ will enter later, which in turn depends on the negotiation outcome at the first round, i.e., the payment $b_{1}$. 
With probability $\beta_{1}, E_{1}$ makes the offer. The entrant $E_{1}$ cannot demand more than $\hat{b}_{1} \equiv \pi(p)-\left[\alpha \pi^{m}+(1-\alpha) \pi_{P, 1}^{d}\right]$, for the patent-holder can always guarantee herself the threat-point payoff by rejecting the offer and complete the trial. If

$$
S_{2}\left(p, \hat{b}_{1}\right)=(1-\alpha)\left(\pi_{P, 1}^{d}-\pi_{P}^{t}-\pi_{2}^{t}\right) \leq 0,
$$

then $\hat{b}_{1}$ suffices to deter $E_{2}$ 's entry. $E_{1}$ will optimally demand a payment $\hat{b}_{1}$ and the patent-holder will accept with a payoff the same as at the threat point. To reduce the number of cases to be considered, from now on we shall assume that condition (21) holds. (This will be the case, for instance, when firms offer homogeneous goods and engage in Cournot competition with linear demand and zero marginal cost.) ${ }^{32}$

With probability $1-\beta_{1}$, the patent-holder makes the offer. Without other concerns, the patent-holder will offers a payment $b_{1}^{*} \equiv(1-\alpha) \pi_{1}^{d}$, i.e., $E_{1}$ 's threat-point payoff. However, if the antitrust policy is sufficiently lenient, then the bargaining surplus will be positive at round two,

$$
S_{2}\left(p, b_{1}^{*}\right)=\pi(p)-\alpha \pi^{m}-(1-\alpha)\left(\pi_{1}^{d}+\pi_{P}^{t}+\pi_{2}^{t}\right)>0,
$$

and $E_{2}$ may want to enter. The patent-holder, then, may have an incentive to raise the payment to $E_{1}$ in order to deter $E_{2}$ 's entry.

Consider two situations. When the patent-holder chooses $b_{1}=b_{1}^{*}$, the expected return from entering for $E_{1}$ is

$$
\beta_{1} \hat{b}_{1}+\left(1-\beta_{1}\right) b_{1}^{*}=(1-\alpha) \pi_{1}^{d}+\beta_{1}\left[\pi(p)-\alpha \pi^{m}-(1-\alpha)\left(\pi_{P, 1}^{d}+\pi_{1}^{d}\right)\right] \equiv f_{1}^{*} .
$$

$E_{1}$ will enter when $\pi_{1}^{d}<f_{1} \leq f_{1}^{*}$. Given $b_{1}^{*}$, $E_{2}$ will enter for $\pi_{2}^{d}<f_{2} \leq(1-\alpha) \pi_{2}^{t}+$ $\beta_{2} S_{2}\left(p, b_{1}^{*}\right) \equiv f_{2}^{*}$. But if $f_{2}>f_{2}^{*}, E_{2}$ will stay off the market after observing $b_{1}^{*}$. The patent-holder needs not to engage in entry deterrence, and will optimally offer $b_{1}^{*}$ to $E_{1}$ and obtain a payoff $\pi(p)-b_{1}^{*}$ when it's her turn to make the offer at the first round.

32 If condition (21) is violated, then there is a range of $f_{2}$ such that $E_{2}$ will enter following $E_{1}$ 's offer of $\hat{b}_{1}$. For this range of $f_{2}$, accepting $E_{1}$ 's offer and settle the case is not the end of the story for the patent-holder. She still has to face the challenge from $E_{2}$, with an expected payoff

$$
\begin{aligned}
& \alpha \pi^{m}+(1-\alpha) \pi_{P}^{t}+(1-\beta) S_{2}\left(p, \hat{b}_{1}\right)=\alpha \pi^{m}+(1-\alpha) \pi_{P}^{t}+\left(1-\beta_{2}\right)(1-\alpha)\left(\pi_{P, 1}^{d}-\pi_{P}^{t}-\pi_{2}^{t}\right) \\
< & \alpha \pi^{m}+(1-\alpha) \pi_{P, 1}^{d} .
\end{aligned}
$$

The patent-holder will reject the offer $\hat{b}_{1}$. In response, $E_{1}$ has to lower the payment, and so will have less incentives to enter. Note that $E_{1}$ won't be able to demand a higher payment in order to deter $E_{2}$ 's entry. To deter entry, the payment should strictly larger than $\hat{b}_{1}$, but then the patent-holder will prefer to litigate and not settle the case. 
Suppose that $\pi_{2}^{c}<f \leq f_{2}^{*}$ and so $b_{1}^{*}$ is not large enough to deter $E_{2}$ 's entry. Offering $b_{1}^{*}$ then opens future bargaining with $E_{2}$; the patent-holder's expected payoff is $\alpha \pi^{m}+(1-\alpha) \pi_{P}^{t}+\left(1-\beta_{2}\right) S_{2}\left(p, b_{1}^{*}\right)$. To deter $E_{2}$ 's entry, the patent-holder needs to offer $b_{1}^{*}+D$ such that $f_{2} \equiv(1-\alpha) \pi_{2}^{t}+\beta_{2} S_{2}\left(p, b_{1}^{*}+D\right) .{ }^{33}$ The extra amount is

$$
D=\pi(p)-\alpha \pi^{m}-(1-\alpha)\left(\pi_{1}^{d}+\pi_{P}^{t}+\pi_{2}^{t}\right)-\frac{1}{\beta_{2}}\left[f_{2}-(1-\alpha) \pi_{2}^{t}\right] \geq 0 .
$$

The patent-holder's payoff from offering the entry-deterrence payment $b_{1}^{*}+D$ is $\pi(p)-$ $b_{1}^{*}-D$. Comparing the payoffs, it is optimal to deter $E_{2}$ 's entry when

$$
\begin{aligned}
& \pi(p)-b_{1}^{*}-D>\alpha \pi^{m}+(1-\alpha) \pi_{P}^{t}+\left(1-\beta_{2}\right) S_{2}\left(p, b_{1}^{*}\right) \\
\Rightarrow & f_{2}>(1-\alpha) \pi_{2}^{t}+\beta_{2}\left[\left(1-\beta_{2}\right) S_{2}\left(p, b_{1}^{*}\right)-(1-\alpha) \pi_{2}^{t}\right] \equiv f_{2}^{D} .
\end{aligned}
$$

A lower $f_{2}$ implies a higher cost to deter $E_{2}$ 's entry, as the payment $b_{1}^{*}+D$ to $E_{1}$ becomes larger. Only when $f_{2} \in\left(f_{2}^{D}, f_{2}^{*}\right]$ will it be necessary and profitable for the patent-holder to deter entry. Note that a higher payment in turn raises $E_{1}$ 's incentive to enter: expecting an offer $b_{1}^{*}+D$ from the patent-holder offers, $E_{1}$ will incur $f_{1}$ such that $\pi_{1}^{c}<f_{1} \leq f_{1}^{*}+\left(1-\beta_{1}\right) D \equiv f_{1}^{D}$, where $D$ is defined as in condition (25).

Equipped with these cut-offs $f_{i}^{*}, f_{i}^{D}, i=1,2$, and $f_{2}^{* *}$, we can find the entry patterns according to the level of entry cost $f_{1}$ and $f_{2}$. From the derivations of different cut-offs, we've known that $f^{D}>f_{1}^{*}$ and $f_{2}^{*}>f_{2}^{D}$. In addition, it can be shown that

$$
f_{2}^{* *}=f_{2}^{*}+(1-\alpha)\left[\left(1-\beta_{2}\right)\left(\pi_{2}^{d}-\pi_{2}^{t}\right)+\beta_{2}\left(\pi_{1}^{d}+\pi_{P}^{t}-\pi_{P, 2}^{d}\right)\right] .
$$

As long as $\pi_{P, 2}^{d}$ is not too large, then we have $f_{2}^{* *}>f_{2}^{*}>f_{2}^{D}$. Suppose this is true. With the additional assumption that $f_{1}^{*}>\pi_{1}^{d}$ and $f_{2}^{D}>\pi_{2}^{d}$, we summarize the result in Figure 2.

Consider different ranges of entry cost $f_{1}$ and $f_{2}$. We may find both entrants entering only for $f_{1} \in\left(\pi_{1}^{d}, f_{1}^{*}\right]$ and $f_{2} \in\left(\pi_{2}^{d}, f_{2}^{D}\right]$. By $f_{1} \leq f_{1}^{*}, E_{1}$ will enter whether the patent-holder offers the deterrence payment $\left(b_{1}^{*}+D\right)$ or not. By $f_{2} \leq f_{2}^{D}$, the patent-holder finds it too costly to deter $E_{2}$ 's entry, and so $E_{2}$ enters with probability $1-\beta_{1}$, when the patent-holder makes the settlement offer at round one. For all other cases: when $f_{1}>f_{1}^{*}$, then $E_{1}$ will not enter without the deterrence payment $b_{1}^{*}+D$ from the patent-holder, and so we won't have both incurring the entry fee; and when

${ }^{33}$ Assuming that $E_{2}$ will enter upon indifference, then to deter entry the patent-holder will need to pay $E_{1}$ with an amount $b_{1}^{*}+D+\varepsilon$, with $\varepsilon>0$ but arbitrarily close to zero. We shall ignore this complication, but instead assume that the patent-holder will deter if and only if it is strictly profitable to do so, as implied in condition (26). 


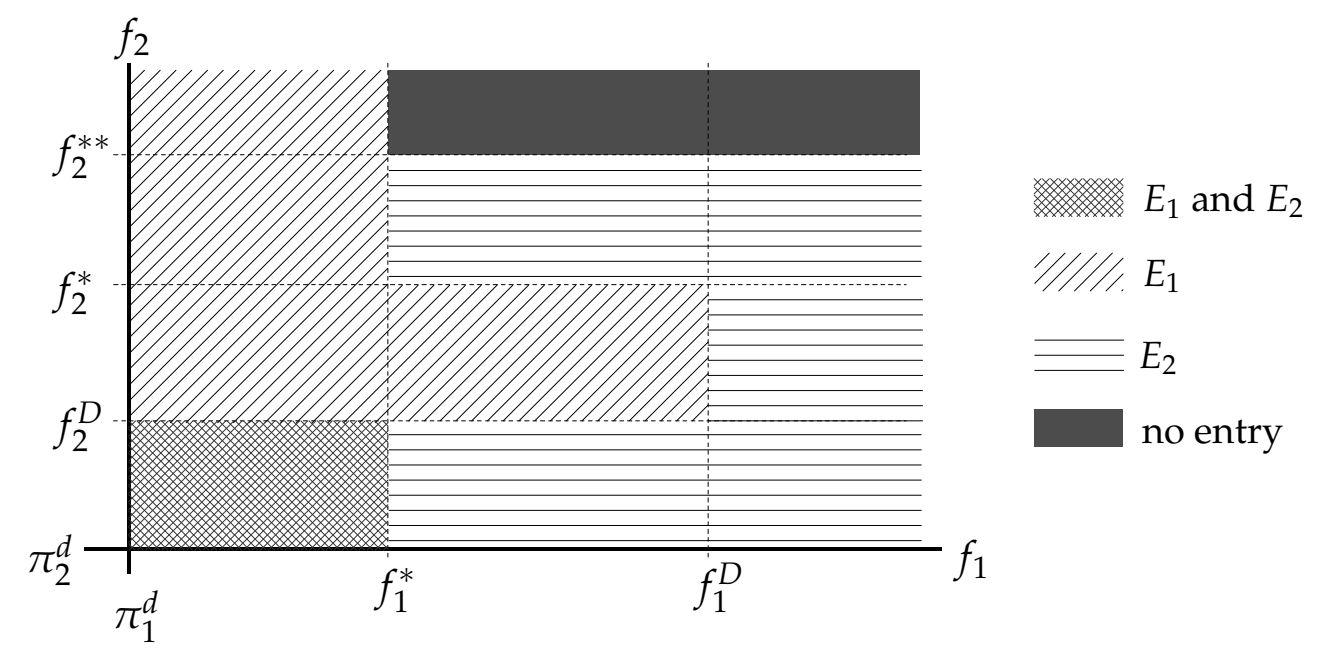

Figure 2: Multiple entrants

$f_{2}>f_{2}^{D}$, either the patent-holder will engage in entry deterrence (for $\left.f_{2} \in\left(f_{2}^{D}, f_{2}^{*}\right]\right)$, or $E_{2}$ will not enter as long as $E_{1}$ has already entered (for $f_{2}>f_{2}^{*}$ ). It is also interesting to notice that whether $E_{2}$ enters may not be monotonic in the entry cost $f_{2}$. Fix $f_{1} \in\left(f_{1}^{*}, f_{1}^{D}\right] . E_{1}$ enters if and only if the patent-holder will offer the deterrence payment, and the latter will do so if and only if $f_{2}$ lies in the range $\left(f_{2}^{D}, f_{2}^{*}\right]$. When $f_{2}$ is too small $\left(f_{2} \in\left(\pi_{2}^{d}, f_{2}^{D}\right]\right)$, the patent-holder will not deter $E_{2}$ and so only $E_{2}$, but not $E_{1}$, will enter. When $f_{2}$ is large enough $\left(f_{2} \in\left(f_{2}^{*}, f_{2}^{* *}\right]\right), E_{2}$ will not enter when the patent-holder offers $E_{1}$ the payment $b_{1}^{*}$. The patent-holder does not have to offer the deterrence payment. But expecting the payment $b_{1}^{*}, E_{1}$ will choose not to enter; only $E_{2}$ enters (for $f_{2} \leq f_{2}^{* *}$ ).

For our purpose, nevertheless, it suffices to notice that all the cut-offs are increasing in $\pi(p)$ and so in the antitrust policy $p$. In this sequential entry scenario, a more lenient policy still raises entrants' incentive to enter for buyout. In addition, whenever condition (21) holds, the cut-off $f_{1}^{*}$ is identical to the corresponding cut-off we've derived in the single-entrant case. Sequential entry, then, will not reduce the extent of strategic entry. Given the same antitrust policy $p$, social welfare (weakly) decreases under sequential entry than under single-entrant due to the extra entry fee incurred by the additional entrant. ${ }^{34}$

Remark 7. Suppose that the settlement agreement between at the first round remains

\footnotetext{
${ }^{34}$ The failure of condition (21) is relevant only when $E_{2}$ will enter under the round one payment $\hat{b}_{1}$. In this case, although $E_{1}$ 's entry incentives reduce in expectation of a lower payment (see footnote 32), we'll have a simultaneous increase in the cost as the entry fee incurred by $E_{2}$.
} 
valid even after the bargaining breakdown at the second round. Then at the bargaining between the patent-holder and $E_{2}$, the cooperative payoff is still $\pi(p)-b_{1}$, but the patent-holder's threat point payoff reduces to $\alpha \pi^{m}+(1-\alpha) \pi_{P}^{t}-b_{1}$. Bargaining surplus becomes $\pi(p)-\left[\alpha \pi^{m}+(1-\alpha)\left(\pi_{P}^{t}+\pi_{2}^{t}\right)\right]$, not affected by $b_{1}$. $E_{2}$ 's expected payoff $b_{2}$ and thus entry decision are not affected by the bargaining terms in the previous negotiation. The patent-holder cannot use $b_{1}$ to deter $E_{2}$ 's entry, and so will always offer $b_{1}=b_{1}^{*}$ when having the opportunity at the first round. The optimal settlement offer of $E_{1}$, however, is different.

At the first round, the patent-holder's threat point payoff is $\alpha \pi^{m}+(1-\alpha) \pi_{P, 1}^{d}$, the same as before, but her cooperative payoff becomes the expected payoff at round two, namely, $\alpha \pi^{m}+(1-\alpha) \pi_{P}^{t}+\left(1-\beta_{2}\right) S_{2}\left(p, b_{1}\right)$. To induce acceptance, $E_{1}$ 's offer has to satisfy

$$
\begin{gathered}
\alpha \pi^{m}+(1-\alpha) \pi_{P}^{t}+\left(1-\beta_{2}\right) S_{2}\left(p, b_{1}\right) \geq \alpha \pi^{m}+(1-\alpha) \pi_{P, 1}^{d} \\
\Rightarrow b_{1} \leq \pi(p)-\alpha \pi^{m}-(1-\alpha)\left(\pi_{P}^{t}+\pi_{2}^{t}\right)-\frac{1-\alpha}{1-\beta_{2}}\left(\pi_{P, 1}^{d}-\pi_{P}^{t}\right) .
\end{gathered}
$$

$E_{1}$ 's incentive to entry has to be modified accordingly. But since this upper-bound is increasing in $\pi(p)$, a more lenient $p$ still raises incentives to enter.

Divisible entry cost: Here we assume divisible entry cost and consider an alternative construction of the standing requirement discussed in Remark 2. Suppose that, in order to be eligible to bring a suit to invalidate the patent, the entrant has to incur at least $f_{0} \in(0, f]$ of the entry cost. We compare the welfare impact of this requirement with the case where this requirement is abolished, i.e., when $f_{0}=0$, whose effect has been analyzed in Proposition 1.

When $f_{0} \leq f \leq \pi_{E}^{c}$, the standing requirement will alter the settlement behavior, but not the entrant's decision to challenge the patent. The entrant is forced to spend $f_{0}$ before the settlement negotiation, and so, at bargaining, the entrant's threat point is raised to $(1-\alpha)\left[\pi_{E}^{c}-\left(f-f_{0}\right)\right]$ while the bargaining surplus reduced to $S(p)+(1-$ $\alpha)\left(f-f_{0}\right)$. Define $\tilde{p}_{0}$ such that $S\left(\tilde{p}_{0}\right) \equiv-(1-\alpha)\left(f-f_{0}\right)$; the two parties will settle if and only if $p \geq \tilde{p}_{0}$. It is easy to verify that $\tilde{p}_{0}>\tilde{p}$ for all $f_{0} \in(0, f]$, i.e., the standing requirement weakens the two parties' settlement incentives.

Concerning the welfare effect, when $p<\tilde{p}$ or $p \geq \tilde{p}_{0}$, the two parties' settlement choice is not affected, but static welfare is lower in the presence of the requirement. This is because the requirement forces the entrant to spend $f_{0}$ even though in the end 
he does not enter the market. When $p<\tilde{p}$, there is no settlement, and social welfare is $\alpha W^{m}+(1-\alpha)\left(W^{c}-f\right)$ without the standing requirement, but reduces to $-f_{0}+$ $\alpha W^{m}+(1-\alpha)\left[W^{c}-\left(f-f_{0}\right)\right]=\alpha W^{m}+(1-\alpha)\left(W^{c}-f\right)-\alpha f_{0}$ under the requirement. When $p \geq \tilde{p}_{0}$, the two parties will settle, and social welfare is $W(p)$ without the standing requirement, but $W(p)-f_{0}$ under the requirement.

When $\tilde{p} \leq p<\tilde{p}_{0}$, introducing the standing requirement prevents settlement. Social welfare is $W(p)$ without the standing requirement, and $\alpha W^{m}+(1-\alpha)\left(W^{c}-\right.$ $f)-\alpha f_{0}$ under the standing requirement. Since at the Shapiro policy $p^{s}, \pi\left(p^{s}\right) \geq$ $\alpha \pi^{m}+(1-\alpha) \pi^{c}>\pi\left(\tilde{p}_{0}\right)$, we must have $p^{s}>\tilde{p}_{0}>p$. Together with the assumption that $W(\cdot)$ is decreasing in the antitrust policy, we then obtain $W(p)>W\left(p^{s}\right)>$ $\alpha W^{m}+(1-\alpha)\left(W^{c}-f\right)-\alpha f_{0}$. The standing requirement $f_{0}$ reduces social welfare.

Suppose that $f>\pi_{E}^{c}$, and so the entrant does not have a credible entry threat with the whole entry cost $f$. To assess the effect of standing requirement $f_{0}$, we first modify the analysis in Section 3 so that the entrant can divide the entry fee with or without the requirement. We show that the optimal expenditure for the entrant to incur at time 0 is $f-\pi_{E}^{c}$, for he only needs to incur $f-\left(f-\pi_{E}^{c}\right)=\pi_{E}^{c}$ at time 3. Any smaller expenditure won't make him credible, and so we only need to establish that it's not optimal for the entrant to spend extra money.

Lemma 1. With $f>\pi_{E}^{c}$ but divisible, to obtain a credible entry threat, the potential entrant's optimal expenditure at time 0 is $f-\pi_{E}^{c}$. The entrant's optimal expected payoff is $-f+\pi_{E}^{c}+$ $\beta\left[S(p)+(1-\alpha) \pi_{E}^{c}\right]$, given that $S(p)+(1-\alpha) \pi_{E}^{c}>0$.

Proof. We've noted that the minimal expenditure required is $f-\pi_{E}^{c}$. Suppose that the entrant spends $\hat{f} \in\left[f-\pi_{E}^{c}, f\right]$ at time 0 , and so $\pi_{E}^{c} \geq(f-\hat{f})$. At the settlement bargaining, his threat point payoff is $(1-\alpha)\left[\pi_{E}^{c}-(f-\hat{f})\right] \geq 0$, and joint surplus is $\pi(p)-\left[\alpha \pi^{m}+(1-\alpha) \pi_{P}^{c}\right]-(1-\alpha)\left[\pi_{E}^{c}-(f-\hat{f})\right]=S(p)+(1-\alpha)(f-\hat{f})$. It is easy to see that the entrant will not spend $\hat{f}$ if joint surplus is negative and so there is no settlement. When there is settlement, given the bargaining power $\beta$, the entrant's payoff is

$$
-\hat{f}+(1-\alpha)\left[\pi_{E}^{c}-(f-\hat{f})\right]+\beta[S(p)+(1-\alpha)(f-\hat{f})] .
$$

Since $\hat{f}$ has negative coefficient, $-1+(1-\alpha)(1-\beta)$, the entrant will want to spend as little as possible; the optimal $\hat{f}=f-\pi_{E}^{c}$. Fixing $\hat{f}$ at this level, and suppose that the two will settle, we then obtain the entrant's payoff.

Q.E.D. 
This lemma also implies that a low standing requirement $f_{0} \leq f-\pi_{E}^{c}$ is irrelevant, for it will not alter the equilibrium outcome. But with a high standing requirement, $f_{0}>f-\pi_{E}^{c}$, the entrant will have to spend $f_{0}$ in order to present his case in court. After this expenditure, his threat point payoff shifts up to $(1-\alpha)\left[\pi_{E}^{c}-\left(f-f_{0}\right)\right]$, and so the bargaining surplus shrinks to $S(p)+(1-\alpha)\left(f-f_{0}\right)$. When the antitrust policy $p$ induces settlement, i.e., when $S(p)+(1-\alpha)\left(f-f_{0}\right) \geq 0$, the entrant's payoff is

$$
-f_{0}+(1-\alpha)\left[\pi_{E}^{c}-\left(f-f_{0}\right)\right]+\beta\left[S(p)+(1-\alpha)\left(f-f_{0}\right)\right]
$$

which is smaller than $-f+\pi_{E}^{c}+\beta\left[S(p)+(1-\alpha) \pi_{E}^{c}\right]$. Facing a binding constraint $f_{0}$, the potential entrant has less incentives to incur $f_{0}$ and challenge the patent.

For the welfare effect, when the antitrust policy $p$ is set so high that the entrant is willing to spend $f_{0}$, he must also be willing to spend $f-\pi_{E}^{c}$ when the standing requirement is abolished. Social welfare is $W(p)-f_{0}$ with the standing requirement, and $W(p)-\left(f-\pi_{E}^{c}\right)$ without the requirement. ${ }^{35}$ Abolishing the requirement saves the partial entry expenditure. But if $p$ is not too high such that the potential entrant is willing to spend $f-\pi_{E}^{c}$, but not $f_{0}$, then social welfare is $W(p)-\left(f-\pi_{E}^{c}\right)$ without the standing requirement, and $W^{m}$ with the standing requirement. A very demanding standing requirement (a high $f_{0}$ ), then, is similar to a stringent antitrust policy and deters the potential entrant from initiating the patent challenge. We may have $W^{m} \gtrless$ $W(p)-\left(f-\pi_{E}^{c}\right)$.

One may wonder whether the standing requirement could be used as an additional, or even more effective policy instrument to deter the potential entrant from incurring wasteful (partial) entry fee. A thorough analysis would need to consider an entrant with different possible levels of entry costs. When the antitrust policy $p$ cannot be made contingent on the true entry cost due to, for instance, asymmetric information, a very high $f_{0}$ indeed may provide additional screening function. However, even in this case, the benefit from enacting a high requirement to deter the entrant with high entry cost should be weighed against all the additional costs the entrant has to bear when he has low entry cost. We remain doubtful about the overall welfare benefit of the standing requirement, and leave the joint determination of optimal antitrust policy and standing requirement for future research.

${ }^{35}$ The case where the antitrust policy is set so low such that the potential entrant does not want to spend $f-\pi_{E}^{c}$ renders the standing requirement irrelevant. 


\section{References}

Bebchuk, L., (1996), "A New Theory Concerning the Credibility and Success of Threats to Sue," Journal of Legal Studies, 25: 1-25.

Besanko, D. and D. Spulber, (1989), "Antitrust Enforcement under Asymmetric Information," Economic Journal, 99: 408-25.

Binmore, K., A. Rubinstein, and A. Wolinsky, (1986), “The Nash Bargaining Solution in Economic Modeling," Rand Journal of Economics, 17 (2): 176-88.

Cosnita, A. and J.-P. Tropeano, (2006), "Negotiating Remedies: Revealing the Merger Efficiency Gains," working paper.

Daughety, A. "Settlement," Encyclopedia of Law and Economics, B. Bouckaert and G. De Geest eds., Edward Elgar, forthcoming.

Graham, S., B. Hall, D. Harhoff and D. Mowery (2003), "Post-Issue Patent Quality Control: A Comparative Study of U.S. Patent Re-Examinations and European Patent Oppositions," Patents in the Knowledge-Based Economy, W. Cohen and S. Merrill eds., Washington, D.C.: the National Academies Press.

Hovenkamp, H., M. Janis, and M. Lemley, (2003), "Anticompetitive Settlement of Intellectual Property Disputes," Minnesota Law Review, 87(6): 1719-61.

Hovenkamp, H., M. Janis, and M. Lemley, (2004), IP and Antitrust: An Analysis of Antitrust Principles Applied to intellectual Property Law, Aspen Law and Business.

Lanjouw, J. and J. Lerner, (2001), “Tilting the Table? The Use of Preliminary Injunctions," Journal of Law and Economics, 44 (2): 573-603.

Lemley, M. and C. Shapiro (2005), "Probabilistic Patents," Journal of Economic Literature, 19(2): 75-98..

Maurer, S. and S. Scotchmer, (2006), "Profit Neutrality in Licensing: The Boundary between Antitrust Law and Patent Law," American Law and Economics Review, 8 (3): 476-522.

Merges, R., (1997), Patent Law and Policy: Cases and Materials, 2nd ed., Michie. 
Meurer, M., (1989), "The Settlement of Patent Litigation," Rand Journal of Economics, 20(1): 77-91.

Rasmusen, E. (1988), “Entry for Buyout," Journal of Industrial Economics, 36(3): 281-99.

Rasmusen, E. (1998), “Nuisance Suits," The New Palgrave Dictionary of Economics and the Law: 2, P. Newman ed., London: MacMillan.

Rey, P., (2003), "Toward a Theory of Competition Policy," Advances in Economics and Econometrics: Theory and Applications, Eighth World Congress, M. Dewatripont, L. Hansen, and S. Turnovsky eds., Cambridge University Press.

Rosenberg, D. and S. Shavell, (2006), "A Solution to the Problem of Nuisance Suits: The Option to Have the Court Bar Settlement," International Review of Law and Economics, 26 (1): 42-51.

Shapiro, C., (2003), "Antitrust Limits to Patent Settlements," Rand Journal of Economics, 34(2): 391-411.

Spier, K. (2007), "Litigation," Handbook of Law and Economics, M. Polinsky and S. Shavell ed., Elsevier. 